\title{
Development and characterization of microsatellite loci for Tabebuia cassinoides (Bignoniaceae)
}

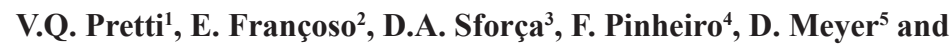

L.G. Lohmann ${ }^{1}$

${ }^{1}$ Laboratório de Sistemática Vegetal, Departamento de Botânica, Instituto de Biociências, Universidade de São Paulo, São Paulo, SP, Brasil ${ }^{2}$ Laboratório de Genética e Evolução de Abelhas, Departamento de Genética e Biologia Evolutiva, Instituto de Biociências, Universidade de São Paulo, São Paulo, SP, Brasil

${ }^{3}$ Laboratório de Análise Genética e Molecular, Centro de Biologia Molecular e Engenharia Genética, Universidade Estadual de Campinas, Campinas, SP, Brasil ${ }^{4}$ Instituto de Botânica, São Paulo, SP, Brasil ${ }^{5}$ Laboratório de Biologia Evolutiva e Conservação de Vertebrados, Departamento de Genética e Biologia Evolutiva, Instituto de Biociências, Universidade de São Paulo, São Paulo, SP, Brasil

Corresponding authors: V.Q. Pretti / L.G. Lohmann E-mail: vaniapretti@gmail.com / 1lohmann@usp.br

Genet. Mol. Res. 13 (3): 5601-5605 (2014)

Received July 25, 2013

Accepted December 17, 2013

Published July 25, 2014

DOI http://dx.doi.org/10.4238/2014.July.25.15

ABSTRACT. Tabebuia cassinoides (Lam.) DC., popularly known as caxeta, is a tree species that belongs to the plant family Bignoniaceae. This species is endemic to the Brazilian Atlantic Forest and is widely exploited commercially. To date, little is known about its genetic structure, preventing the establishment of adequate management plans for this taxon. The objective of this study was to construct a microsatellite-enriched genomic library for $T$. cassinoides to 
select polymorphic loci, and standardize polymerase chain reaction amplification conditions. Of the 15 loci examined, 5 were polymorphic. The number of alleles per locus ranged from 2 to 8 , with a mean of 4.4. The microsatellite loci described here represent the basis for detailed population genetic studies of this species, which will greatly contribute for the development of better conservation strategies for this taxon.

Key words: Brazilian Atlantic Forest; Microsatellite primers; Bignoniaceae; Tabebuia cassinoides

\section{INTRODUCTION}

Tabebuia cassinoides (Lam.) DC. is a tree from the swampy forests of the Atlantic Rain Forest of eastern Brazil, which occurs from the State of Paraná to the northern portions of the State of Espírito Santo (Gentry, 1992). This species is popularly known as caxeta because of its durable wood that is often used to produce boxes ("caixas" in Portuguese). Despite its economic importance, little is known about the genetic structure of $T$. cassinoides along the Atlantic Rainforest of Brazil, preventing the establishment of adequate management plans for this taxon.

Plant population genetic studies have increased substantially in the past years (Collevatti et al., 2012; Diniz-Filho et al., 2012; Pinheiro et al., 2010, 2011, 2013). Yet, the development of molecular markers with adequate levels of variation to investigate the genetic structure within and among populations remains one of the greatest limitations of these types of studies. More recently, special attention has been devoted to microsatellite loci (Sunnucks, 2000), which are thought to be selectively neutral (Schlötterer, 1998) and to present high levels of polymorphism and variation. The objective of this study was to develop a set of polymorphic microsatellite markers for $T$. cassinoides to be used as the basis to describe the genetic structure of the various populations of this threatened species.

\section{MATERIAL AND METHODS}

Total DNA was extracted from silica-dried leaves of T. cassinoides using the DNA extraction kit Invisorb spin plant mini kit (Invitek-Berlin, Berlin, Germany) and following the manufacturer protocol with minor modifications. Marker isolation involved the construction of a genomic library that was partially enriched for $(\mathrm{CT})_{\mathrm{n}}$ and $(\mathrm{GT})_{\mathrm{n}}$ repeats through the use of biotinylated oligonucleotide sequences bound to streptavidin-coated magnetic particles (Kijas et al., 1994) and the modifications suggested by Billotte et al. (1999). DNA fragments enriched with microsatellites were combined with the vector pGEM-T Easy (Promega) as described by the supplier, and the product was used to transform competent cells of Escherichia coli XL1-Blue. Ninety-six recombinant colonies were obtained and sequenced by Macrogen (South Korea).

Geneious Pro 5.3.5 (Drummond et al., 2011) was used to edit forward and reverse sequences and to locate the regions containing microsatellites with the Phobos plugin (Mayer, 2010). Primers were designed using the Primer 3 software (Rozen and Skaletsky, 2000). Among the clones containing microsatellite regions, 19 allowed primer design. Forward primers were synthesized with a 19-bp long, 5' M13 tail (5'-CACGACGTTGTAAAACGAC-3') by the 
method of Schuelke (2000).

To determine polymerase chain reaction (PCR) amplification conditions and general genetic parameters, we analyzed 67 individuals from two Brazilian populations: Linhares (36 samples) and Iguape (31 samples). Total DNA was extracted following the procedures described above. PCRs were performed following the protocols described by Francisco et al. (2011) and using the following amplification conditions: $94^{\circ} \mathrm{C}$ for $3 \mathrm{~min} ; 35$ cycles of $94^{\circ} \mathrm{C}$ for $30 \mathrm{~s}, 60^{\circ} \mathrm{C}$ for $1 \mathrm{~min}$ or $54^{\circ} \mathrm{C}$ for $1 \mathrm{~min}$ (Table 1 ), and $72^{\circ} \mathrm{C}$ for $1 \mathrm{~min}$; and $72^{\circ} \mathrm{C}$ for 10 min. PCR products were separated by electrophoresis in an Applied Biosystems 3730 Genetic Analyzer. GeneScan 500 LIZ (Applied Biosystems) was used as a size standard.

\begin{tabular}{|c|c|c|c|c|c|c|c|c|c|c|}
\hline \multirow[t]{2}{*}{ Locus } & \multirow[t]{2}{*}{ Primer sequences } & \multirow[t]{2}{*}{ T(A) } & \multirow[t]{2}{*}{ Repeat } & \multirow[t]{2}{*}{$N_{\mathrm{A}}$} & \multirow[t]{2}{*}{ Size (bp) } & \multicolumn{2}{|c|}{ Iguape } & \multicolumn{2}{|c|}{ Linhares } & \multirow[t]{2}{*}{ GenBank } \\
\hline & & & & & & $H_{\mathrm{O}}$ & $H_{\mathrm{E}}$ & $H_{\mathrm{O}}$ & $H_{\mathrm{E}}$ & \\
\hline Tcass B5 & $\begin{array}{l}\text { (F) ACAAGTCTTAACCTTTTCAGATGC } \\
\text { (R) ACAGGCACCTCAGATTTAGAAC }\end{array}$ & 54 & $(\mathrm{CT})_{15} \mathrm{CCCT}(\mathrm{CT})_{4}$ & 8 & $238-254$ & 0.0869 & $0.4917^{*}$ & 0.6666 & 0.6685 & JQ905595 \\
\hline Tcass B11 & $\begin{array}{l}\text { (F) GCCAGCAGGACGGTTGTGAT } \\
\text { (R)TGGCGTCATCCCGCTCTATG }\end{array}$ & 54 & $(\mathrm{AG})_{2} \mathrm{AC}(\mathrm{AG})_{8}$ & 5 & $212-234$ & 0.3333 & 0.4028 & 0.7272 & $0.4806^{*}$ & JQ905596 \\
\hline Tcass E2 & (F) TGGAGTTGGGATTTCCCCGTTGA & 60 & $\begin{array}{l}\operatorname{TTTC}(\mathrm{T})_{6}(\mathrm{TC})_{2} \\
(\mathrm{TTC})_{4}(\mathrm{TC})_{8}(\mathrm{~T})_{4} \mathrm{TC}\end{array}$ & 3 & $265-278$ & 0.57143 & 0.5785 & 0.1176 & 0.1123 & JQ905597 \\
\hline Tcass F9 & $\begin{array}{l}\text { (R) ACAACGACACTCTGGTGAATCTTGC } \\
\text { (F) ACCCAAAGCTCCCAAAGCAGCA } \\
\text { (R) CAGGTTCGTCGCTTGGCTATGGA }\end{array}$ & 54 & $(\mathrm{GA})_{11}$ & 2 & $222-226$ & 0.45833 & 0.4388 & Mono & Mono & JQ905598 \\
\hline Tcass H3 & $\begin{array}{l}\text { (F) GAGAATCCTGAGGCGATAACATGAGGT } \\
\text { (R) ACATGCAAATGGTGGCCTTAATCAGA }\end{array}$ & 54 & $(\mathrm{CATA})_{2} \mathrm{CAT}(\mathrm{GA})_{12}$ & 4 & $193-207$ & 0.0434 & $0.2637 *$ & 0.5128 & 0.4315 & JQ905599 \\
\hline
\end{tabular}

$\mathrm{T}(\mathrm{A})=$ optimal annealing temperature in ${ }^{0} \mathrm{C} ; N_{\mathrm{A}}=$ number of alleles; $H_{\mathrm{O}}=$ observed heterozygosity; $H_{\mathrm{E}}=$ expected heterozygosity; Mono $=$ monomorphic locus. ${ }^{*} \mathrm{P}<0.01$.

GeneMarker 1.85 (SoftGenetics) was used to automatically genotype individuals. The genotypes were verified by visual inspection. Genetic diversity indices were calculated by GenAlEx 6.4 (Peakall and Smouse, 2006), and tests to determine the deviation from HardyWeinberg equilibrium were implemented in ARLEQUIN 3.5 (Excoffier and Lischer, 2010). Linkage disequilibrium was calculated in GENEPOP 4.1 (Rousset, 2008).

The cross-amplification of 21 pairs of primers that were developed for Tabebuia aurea (Silva Manso) Benth. \& Hook.f. ex S. Moore (Braga et al., 2007) was tested in T. cassinoides using the same amplification protocol described above.

\section{RESULTS AND DISCUSSION}

Fifteen of 19 primer pairs amplified their respective loci successfully. Out of these 15 loci, five were polymorphic (Table 1). The number of alleles per locus ranged from two to eight. Expected and observed heterozygosities ranged from 0.1123 to $0.6685($ mean $=0.4298)$ and 0.0434 to 0.7272 (mean $=0.3908)$, respectively. No polymorphisms were encountered at locus Tcass F9 in the population from Linhares (Espírito Santo). Three loci, namely, Tcass B5 and Tcass H3 from Iguape (São Paulo) and Tcass B11 from Linhares (Espírito Santo), showed significant departure from the Hardy-Weinberg equilibrium $(\mathrm{P}<0.001)$, because of the heterozygote deficiency in the population from Iguape and heterozygote excess in the population from Linhares (Table 1). The natural subdivision of populations of $T$. cassinoides may be the 
cause of the disequilibrium that was observed in these loci. No linkage disequilibrium between any pair of loci was detected. The cross-amplification in $T$. cassinoides using primers that were designed for $T$. aurea resulted in seven amplifications for the 21 primer pairs, of which three were polymorphic (14.29\%) (Table 2$)$.

\begin{tabular}{|c|c|c|c|}
\hline Locus & Reference & Status amplification & Result genotyping \\
\hline Tau 07 & Braga et al., 2007 & -- & -- \\
\hline Tau 08 & Braga et al., 2007 & -- & -- \\
\hline Tau 09 & Braga et al., 2007 & -- & -- \\
\hline Tau 10 & Braga et al., 2007 & -- & -- \\
\hline Tau 13 & Braga et al., 2007 & + & -- \\
\hline Tau 14 & Braga et al., 2007 & + & Polymorphic \\
\hline Tau 15 & Braga et al., 2007 & + & Polymorphic \\
\hline Tau 16 & Braga et al., 2007 & -- & -- \\
\hline Tau 17 & Braga et al., 2007 & + & Monomorphic \\
\hline Tau 18 & Braga et al., 2007 & -- & -- \\
\hline Tau 19 & Braga et al., 2007 & -- & -- \\
\hline Tau 20 & Braga et al., 2007 & -- & -- \\
\hline Tau 21 & Braga et al., 2007 & + & Polymorphic \\
\hline Tau 22 & Braga et al., 2007 & + & -- \\
\hline Tau 23 & Braga et al., 2007 & -- & -- \\
\hline Tau 24 & Braga et al., 2007 & -- & -- \\
\hline Tau 27 & Braga et al., 2007 & + & -- \\
\hline Tau 28 & Braga et al., 2007 & -- & -- \\
\hline Tau 30 & Braga et al., 2007 & -- & -- \\
\hline Tau 31 & Braga et al., 2007 & -- & -- \\
\hline
\end{tabular}

Successful amplifications (+) and failed amplifications or genotypings (--) are indicated.

The microsatellite loci of T. cassinoides that were described here represent the basis of further studies on the population genetics and conservation of this taxon (Pretti VQ, Pinheiro F, Meyer D and Lohmann LG, unpublished results). Given the economic importance of $T$. cassinoides, genetic studies of this taxon are especially needed so that adequate management plans can be established.

\section{ACKNOWLEDGMENTS}

We would like to thank Alexandre Rizzo Zuntini for assistance during fieldwork and Drs. Anette P. de Souza, Ana Cristina Bondioli, Daniela Calcagnotto, and Riviane Garcez for assistance during the preparation of the genomic library. We also thank CNPq for a Ph.D. scholarship to V.Q. Pretti (Grant \#142040/2009-6) and a Pq-1D grant to L.G. Lohmann (Grant \#305102/2010-9), FAPESP for a Ph.D. scholarship to E. Françoso (Grant \#2010/20548-2), and CAPES/PROEX for additional funding.

\section{REFERENCES}

Billotte N, Lagoda PJR, Risterucci AM and Baurens FC (1999). Microsatellite-enriched libraries: applied methodology for the development of SSR markers in tropical crops. Fruits 54: 277-288.

Braga AC, Reis AMM, Leoi LT and Pereira RW (2007). Development and characterization of microsatellite markers for the tropical tree species Tabebuia aurea (Bignoniaceae). Mol. Ecol. Notes 7: 53-56.

Collevatti RG, de Castro TG, de Souza LJ and de Campos Telles MP (2012). Phylogeography of Tibouchina papyrus (Pohl) Toledo (Melastomataceae), an endangered tree species from rocky savannas, suggests bidirectional expansion 
due to climate cooling in the Pleistocene. Ecol. Evol. 2: 1024-1035.

Diniz-Filho JAF, Melo DB, Oliveira G and Collevatti RG (2012). Planning for optimal conservation of geographical genetic variability within species. Conserv. Genet. 13: 1085-1093.

Drummond AJ, Ashton B, Buxton S and Cheung M (2011). Geneious 5.3.5. Available at [http://www.geneious.com/]. Accessed June 18, 2013.

Excoffier L and Lischer HE (2010). Arlequin suite ver 3.5: a new series of programs to perform population genetics analyses under Linux and Windows. Mol. Ecol. Resour. 10: 564-567.

Francisco FO, Brito RM, Santiago LR and Gonçalves PHP (2011). Isolation and characterization of 15 microsatellite loci in the stingless bee Plebeia remota (Apidae: Meliponini). Conserv. Genet. Resour. 3: 417-419.

Gentry AH (1992). Flora Neotropica, Monograph 25 (II), Bignoniaceae Part II (Tribo Tecomeae). New York Botanical Garden Press, New York.

Kijas JM, Fowler JC, Garbett CA and Thomas MR (1994). Enrichment of microsatellites from the citrus genome using biotinylated oligonucleotide sequences bound to streptavidin-coated magnetic particles. Biotechniques 16: 656-660, 662.

Mayer C (2010). Phobos v. 3.3.11. Available at [http://www.rub.de/spezzoo/cm/cm_phobos.htm]. Accessed June 18, 2013.

Peakall R and Smouse PE (2006). GENALEX 6: genetic analysis in Excel. Population genetic software for teaching and research. Mol. Ecol. Notes 6: 288-295.

Pinheiro F, De BF, Palma-Silva C, Meyer D, et al. (2010). Hybridization and introgression across different ploidy levels in the Neotropical orchids Epidendrum fulgens and E. puniceoluteum (Orchidaceae). Mol. Ecol. 19: 3981-3994.

Pinheiro F, Barros F, Palma-Silva C and Fay MF (2011). Phylogeography and genetic differentiation along the distributional range of the orchid Epidendrum fulgens: a Neotropical coastal species not restricted to glacial refugia. J. Biogeogr. 38: 1923-1935.

Pinheiro F, Cozzolino S, Barros F and Gouveia TMZM (2013). Phylogeographic structure and outbreeding depression reveal early stages of reproductive isolation in the neotropical orchid Epidendrum denticulatum. Evolution 67: 2024-2039.

Rousset F (2008). GENEPOP'007: a complete re-implementation of the GENEPOP software for Windows and Linux. Mol. Ecol. Resour. 8: 103-106.

Rozen S and Skaletsky HJ (2000). Primer3 on the WWW for General Users and for Biologist Programmers. In: Bioinformatics Methods and Protocols: Methods in Molecular Biology (Krawetz S and Misener S, eds.). Humana Press, Totowa, 365-386.

Schlötterer C (1998). Genome evolution: are microsatellites really simple sequences? Curr. Biol. 8: R132-R134.

Schuelke M (2000). An economic method for the fluorescent labeling of PCR fragments. Nat. Biotechnol. 18: 233-234.

Sunnucks P (2000). Efficient genetic markers for population biology. Trends Ecol. Evol. 15: 199-203. 